
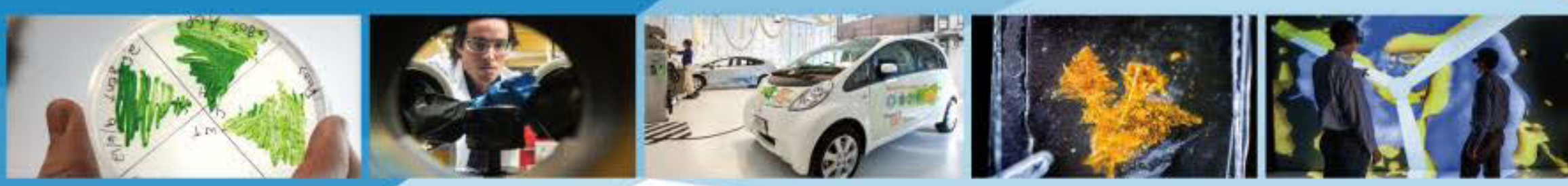

\title{
2018 Annual Technology Baseline (ATB)
}

Laura Vimmerstedt, Chad Augustine, Philipp Beiter, Wesley Cole, David Feldman, Parthiv Kurup, Eric Lantz, Robert Margolis, Ashwin Ramdas, Tyler Stehly, and Craig Turchi (NREL), Patrick O'Connor (ORNL)

Webinar - July 26, 2018

NREL/PR-6A20-71846 
- Project Overview

- Cost and Performance Summary

- Preview of 2018 Standard Scenarios 
Project Overview 


\section{The ATB targets analytic transparency and consistency.}

Objective: Develop and publish renewable energy technology cost and performance scenarios that are credible, comparable, transparent, and reflect potential technology advancement

EERE Analysis Consistency

\section{Third Party Analysis}

- Ensure consistent assumptions across technologies

- Provide comparability across EERE/national laboratory publications

a U.S. Department of Energy Office of Energy Efficiency and Renewable Energy (EERE)

- Provides access to assumptions

- Leverages national laboratory expertise 
Now in its fourth year, the ATB is frequently used at NREL ...

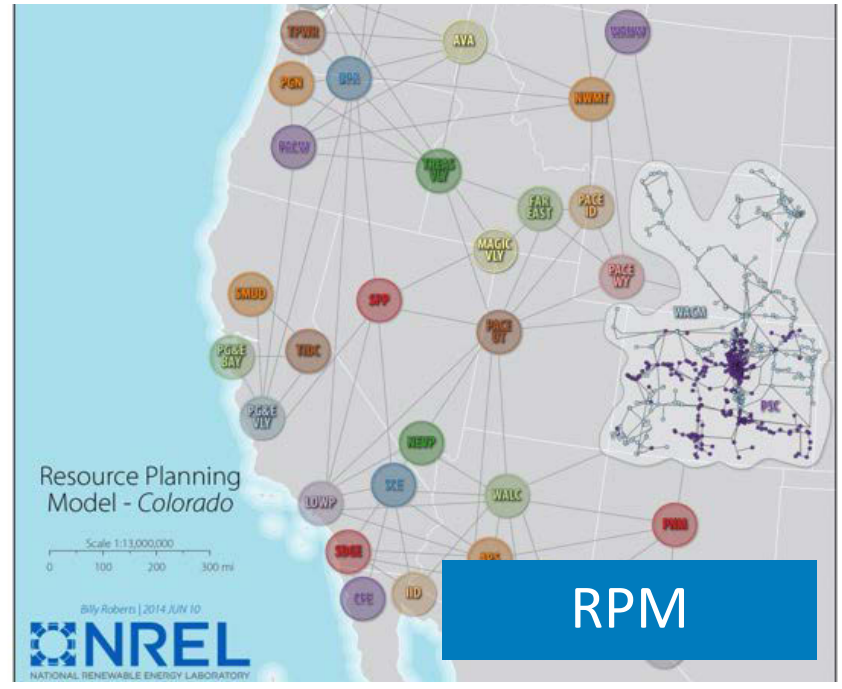

Resource Planning Model

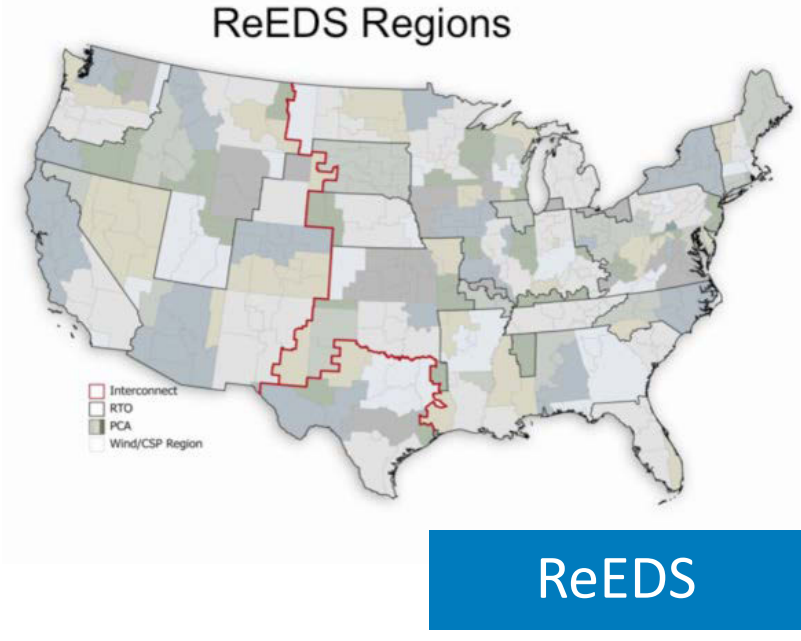

Regional Energy Deployment System

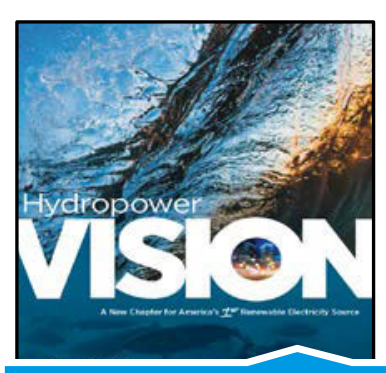

Hydropower Vision

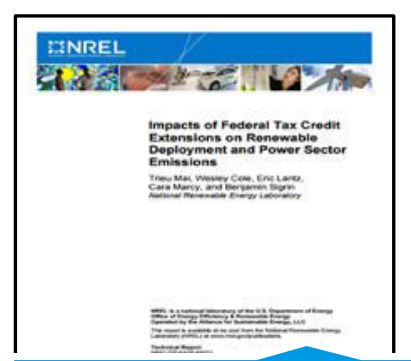

Impacts of Tax Credit Extensions

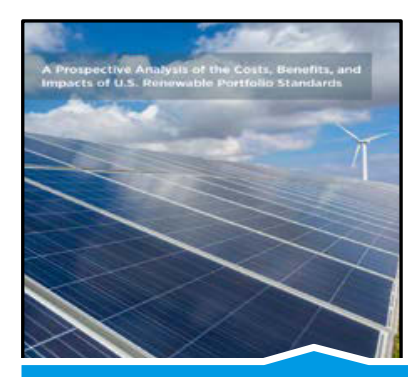

Prospective RPS Cost, Benefits, and Impacts
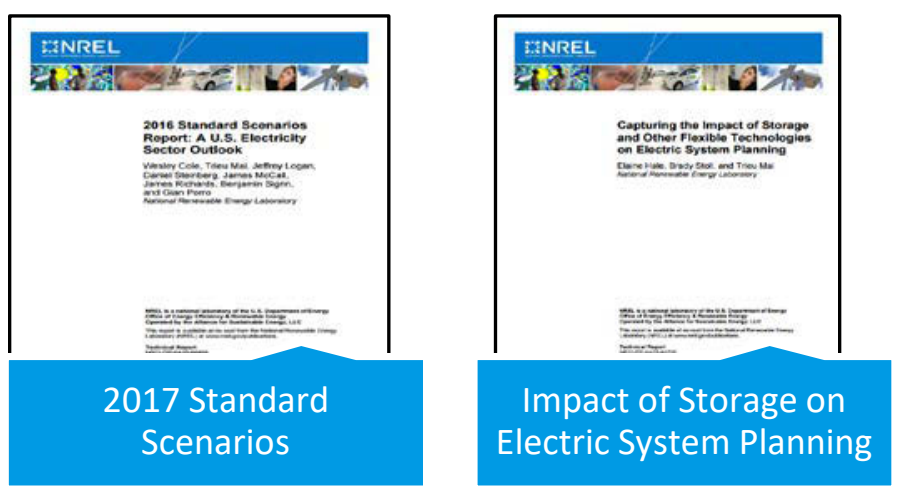

Important Scenario Analyses Used ATB Projections 


\section{... and by planners, academics, analysts, and others.}

\section{Federal Agencies}

(Bureau of Land Management, Department of Energy and Labs, Environmental Protection Agency)

\section{Consultants}

(Rhodium Group, Navigant, M.J. Bradley \& Associates, Analysis Group)

State Energy Offices

(Hawaii, Michigan)

\section{Grid Operators}

(North American Electric Reliability

Corporation, Midcontinent

Independent System Operator,

Pennsylvania-New Jersey-Maryland

Interconnection, New York

Independent System Operator)

\section{Advocacy Groups}

(Resources for the Future, Environmental Defense Fund, Union of Concerned Scientists)

\section{Utilities}

(Hawaii Electric Company, Dominion Energy)

\section{Academia}

(Stanford University, University of Maryland, University of Texas, Duke University)

\section{International}

(Chilean Ministry of Energy, Global Carbon Capture and Storage Institute, Institute, Canadian Institute for Integrated Energy Systems)

\section{Media}

(Utility Dive) 
The ATB includes two products.

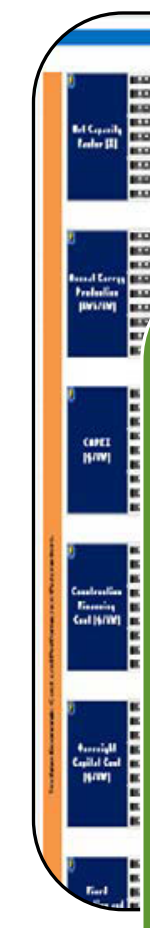

\section{Spreadsheet}

- Cost and performance projections, 2016-2050

- Capacity factor

- Operations and maintenance costs

- Capital expenditures (CAPEX)

- Financing assumptions

- Levelized cost of energy (LCOE)

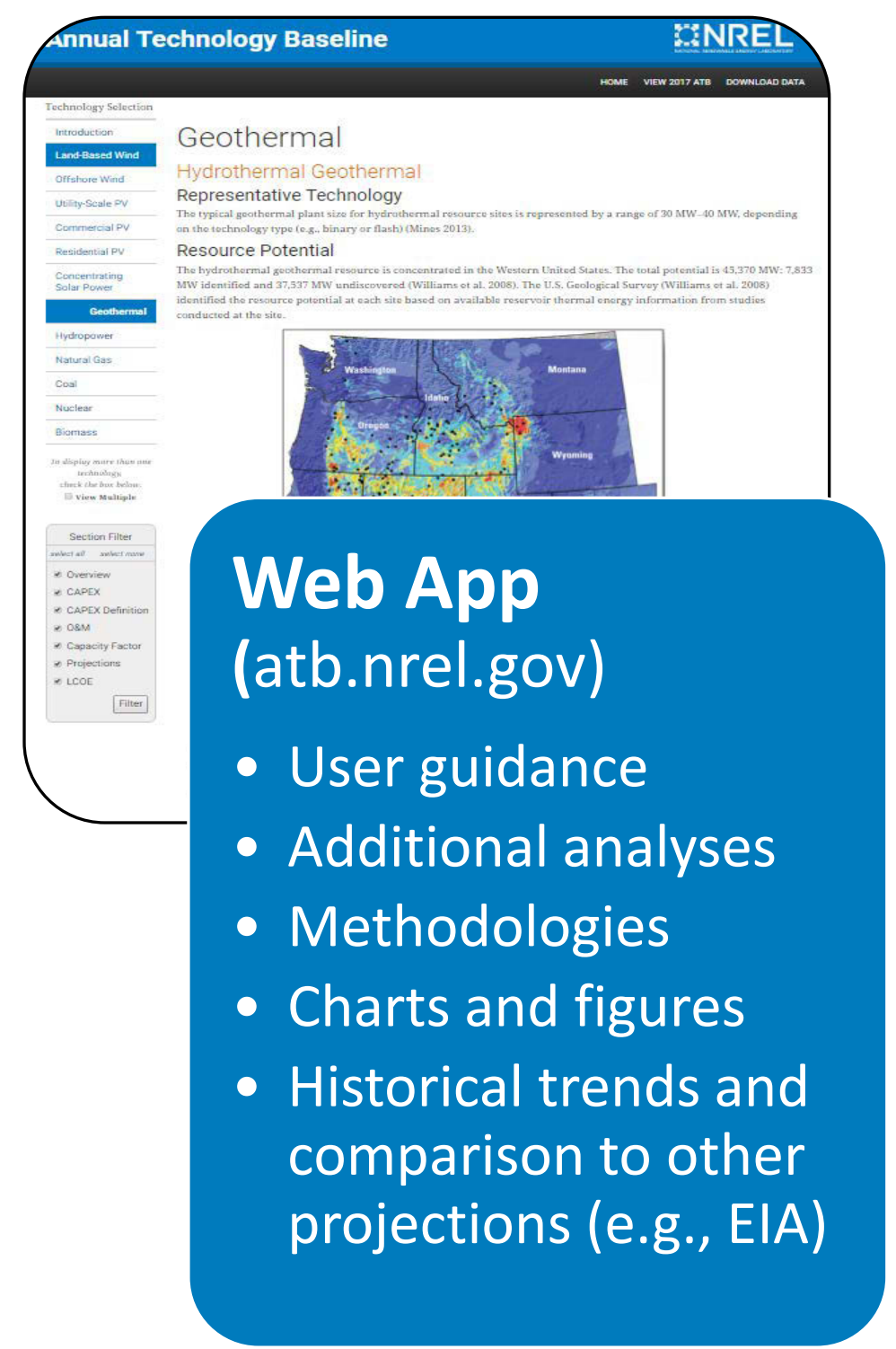




\section{Annual Technology Baseline}

Cost and performance assumptions for renewable and conventional technologies

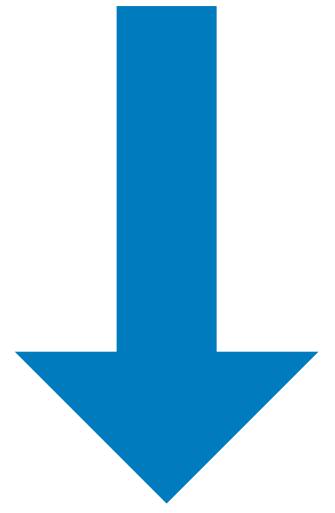

\section{Standard Scenarios}

Ensemble of future scenarios of the

U.S. electric power sector 


\section{The ATB provides cost and performance data.}

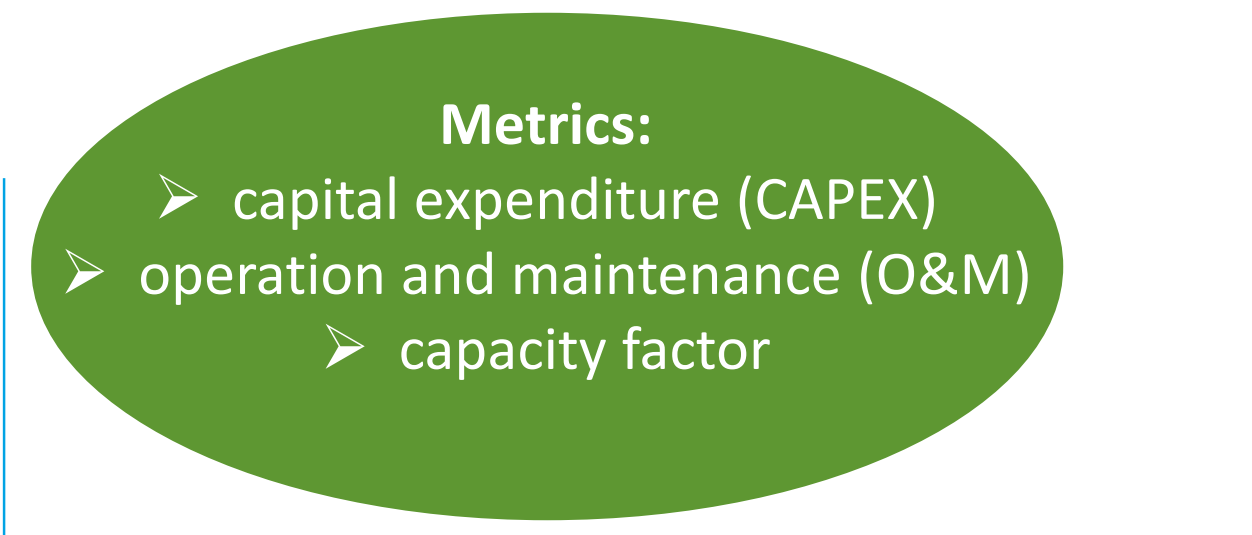

\section{6}

Base Year

Projections to 2050
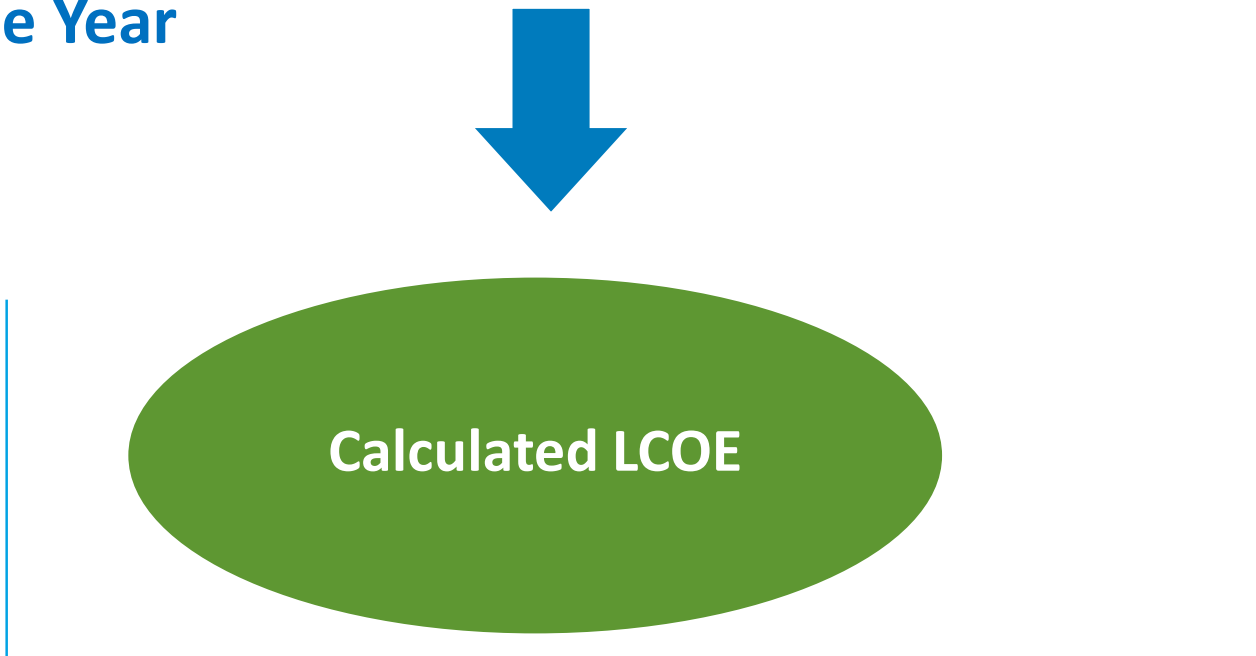

2016

Projections to 2050
Cost and performance data are provided for each

- Year

- Metric

- Resource

- Technology

- Technology cost scenario

- Financial case

... and are used to calculate LCOE for each financial assumptions scenario.

\section{Base Year}




\section{Technologies Covered}

\section{Renewable Energy Technologies}

(Sourced from EERE/NREL)

\section{Wind}

- Land-Based

- Off-Shore

\section{Solar}

- Utility PV

- Commercial and industrial PV

- Residential PV

- Concentrating solar power (CSP)

\section{Hydropower}

- Non-Powered Dams (NPD)

- New Stream-reach Development (NSD)

\section{Geothermal (Flash and Binary)}

- Hydrothermal

- Near-field Enhanced Geothermal Systems (EGS)

- Deep EGS
Conventional and Carbon Capture and Storage

(Sourced from EIA AEO 2018)

\section{Natural Gas}

- Natural gas combined cycle (NGCC)

- NGCC-carbon capture and storage (CCS)

- Combustion turbine (CT)

\section{Coal}

- Conventional

- Integrated gasification combined-cycle (IGCC)

- $30 \%$ CCS

\section{Nuclear}

- Gen 3

\section{Biopower}

- Dedicated

- Co-fired 


\section{Methodology Overview: Three Steps}

\section{Define resource bins for each technology}

Group range of resources for continental United States into bins with common resource quality and characteristics, or develop representative plants

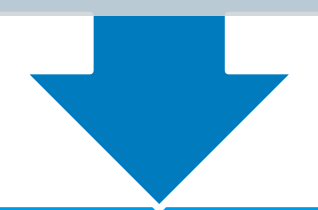

\section{Develop cost and performance data}

Develop base year and projected values for Constant, Mid, and Low technology cost scenarios are developed for CAPEX, capacity factor, and operation and maintenance (O\&M)

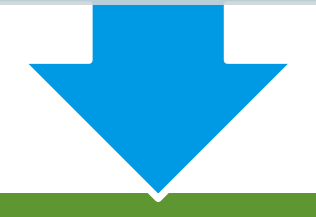

\section{Calculate LCOE}

Use predetermined financial assumptions to calculate LCOE from CAPEX, capacity factor, and O\&M 


\section{Step 1: Define Technologies/Resource Bin Categories}

\begin{tabular}{|c|c|c|}
\hline Technology & Bins & Distinguishing Characteristics \\
\hline Land-based wind & 10 & Annual average wind speed \\
\hline Offshore wind & 15 & $\begin{array}{l}\text { Fixed and floating foundations, distance from shore, water depth, and } \\
\text { annual average wind speed }\end{array}$ \\
\hline $\begin{array}{l}\text { Utility-scale, } \\
\text { commercial, } \\
\text { and residential PV }\end{array}$ & $\begin{array}{l}5 \text { resource } \\
\text { levels }\end{array}$ & Horizontal solar irradiance \\
\hline CSP & 3 & Direct normal solar irradiance \\
\hline Geothermal & $6^{a}$ & Hydrothermal, EGS, binary or flash systems, reservoir temperature \\
\hline Hydropower & $8^{a}$ & $\begin{array}{l}\text { Non-powered dams, new stream-reach development, head, and } \\
\text { design capacity }\end{array}$ \\
\hline Natural gas & 6 & Combustion turbine, IGCC, CCS, and choice of capacity factor \\
\hline Coal & 8 & Pulverized coal, IGCC, CCS percentage, and choice of capacity factor \\
\hline Nuclear & 1 & Not applicable \\
\hline Biopower & 2 & Dedicated or co-fired \\
\hline
\end{tabular}

a Representative bins for the ATB only. ReEDS implements a full site-specific supply curve. 


\section{Example of Technology/Resource Bins: Land-Based Wind}

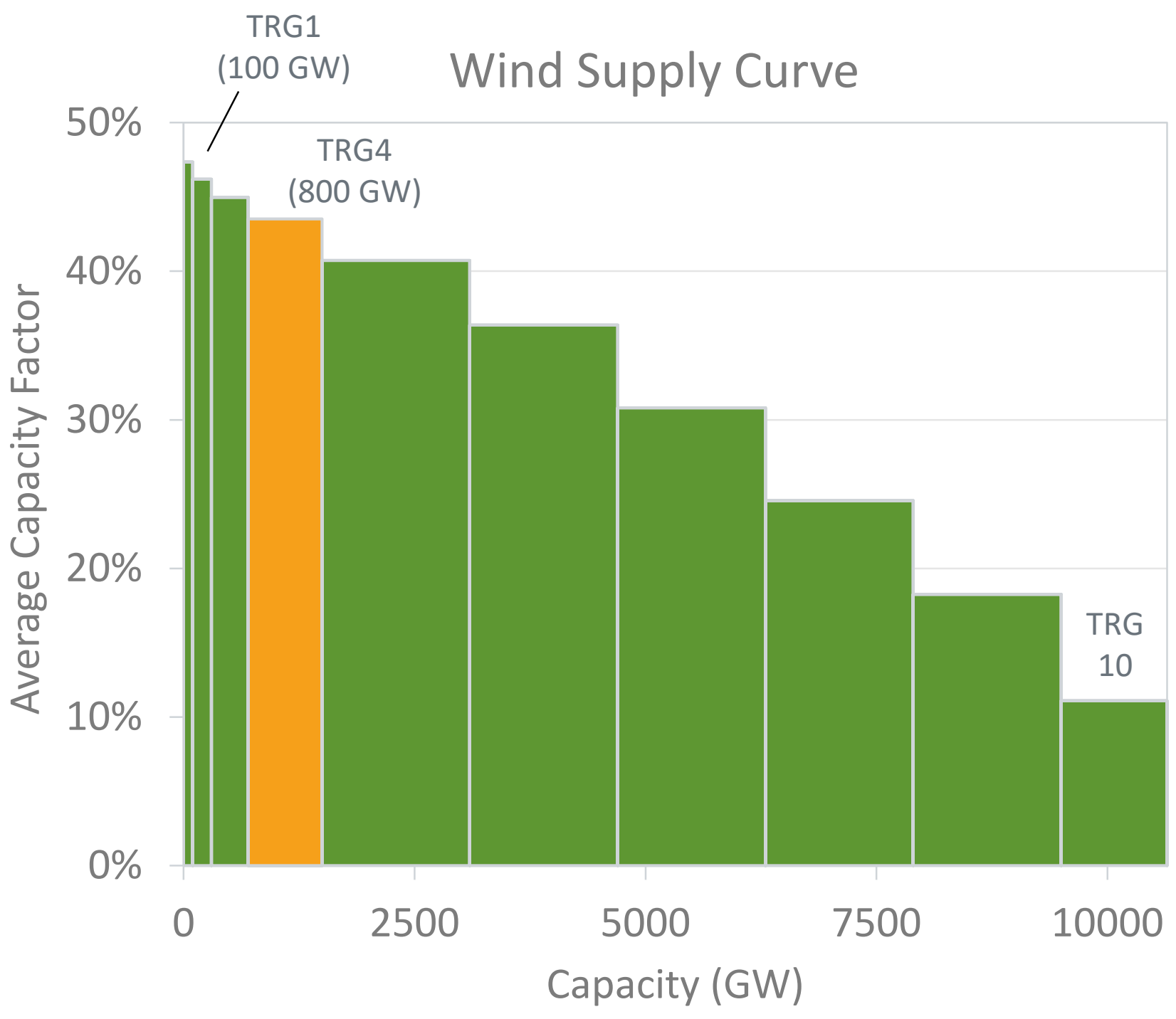

Resources binned by cost and quality into 10 technoresource groups (TRGs)

TRG4 identified as most representative of future installations 
Base Year (2016): Informed by market reports and market data

Projections: Generally rely on published studies; qualitatively harmonized to three projection scenarios:

\section{Constant}

Technology Cost

- Current technology costs held constant

- Represents limited/no technology improvement

- No additional R\&D

\section{Mid \\ Technology Cost}

- Improvements characterized as "likely" or "not surprising"

- Continued public and private R\&D

- Continued deployment and market growth

\section{Low \\ Technology Cost}

- Improvements at the "limit of surprise"

- Not an absolute low bound

- Increased public and private R\&D, breakthroughs

- Accelerated market growth 


\section{Sources of Base Year (2016)}

\section{Technology}

Wind

- Land-based

- Offshore

\section{Solar Photovoltaics (PV)}

- Utility

- Commercial and industrial

- Residential

Market data

Bottom-up model

Market data

Unpublished data

Bottom-up model

Market data

Bottom-up model

- Non-powered Dams

\section{Geothermal}

- Binary and flash - EGS
Bottom-up model

\section{Main Sources}

2016 Wind Technologies Market Report (LBNL 2017)

2016 Cost of Wind Energy Review (NREL 2017)

Assessment of Economic Potential of Offshore Wind in the United States (NREL 2017)

Utility-Scale Solar 2016 (LBNL 2017)

Tracking the Sun 10 (LBNL 2017)

U.S. Solar Photovoltaic System Cost Benchmark: Q1 2017 (NREL 2017)

Utility-Scale Solar 2016 (LBNL)

On the Path to SunShot (DOE/NREL 2016)

Survey of in-development projects (DOE unpublished)

\section{Fossil, Nuclear, and CCS Engineering estimates}

AEO2018 assumptions (EIA 2018) 


\section{Sources of Projections (to 2050)}

\section{Technology}

\section{Wind}

- Land-based

- Offshore

\section{Solar PV}

- Utility

- Commercial and industrial

- Residential

\section{Methods}

Expert elicitation

Bottom-up model

Expert assessment

Literature survey

Bottom-up model

\section{Main Sources}

Expert elicitation survey on future wind energy costs (LBNL 2016)

SMART Wind (NREL 2017)

Internal analysis (Feldman/NREL 2018)

On the Path to SunShot (DOE/NREL 2016)
Market data

CSP

Unpublished data

Bottom-up model

Expert assessment

Learning

\section{Hydropower}

- New stream

- Non-powered Dams
Internal analysis (Kurup/NREL 2018)

On the Path to SunShot (DOE/NREL 2016)
Hydropower Vision (DOE 2016)

NEMS (EIA 2017)

\section{Geothermal}

- Binary and flash

- EGS

\section{Fossil, Nuclear, and CCS}

Learning
Same as ATB 2017. Will be updated after Geothermal Vision Study is published. 


\section{Example of Developing Future Scenarios: Land-Based Wind}

Capacity Factor

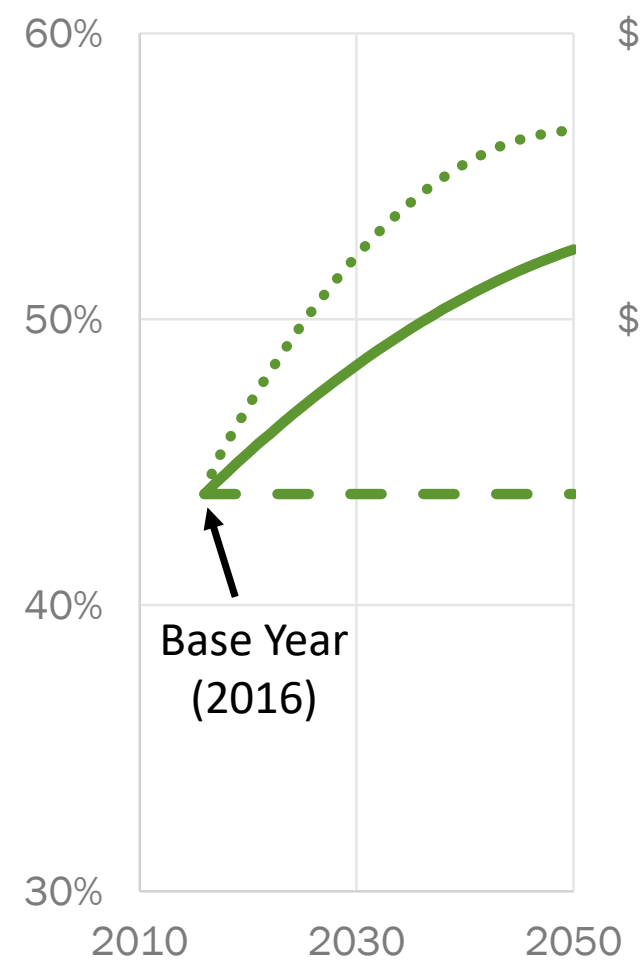

$\operatorname{CAPEX}(\$ / \mathrm{kW})$

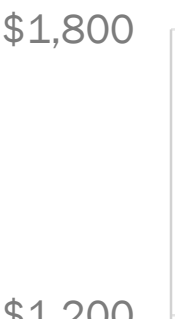

$\$ 600$
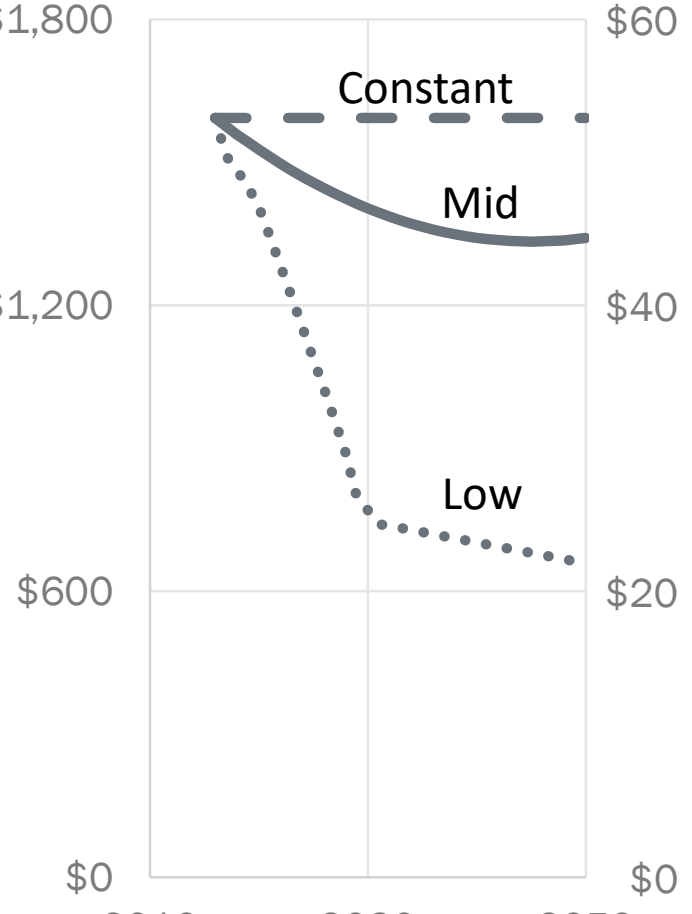

2010

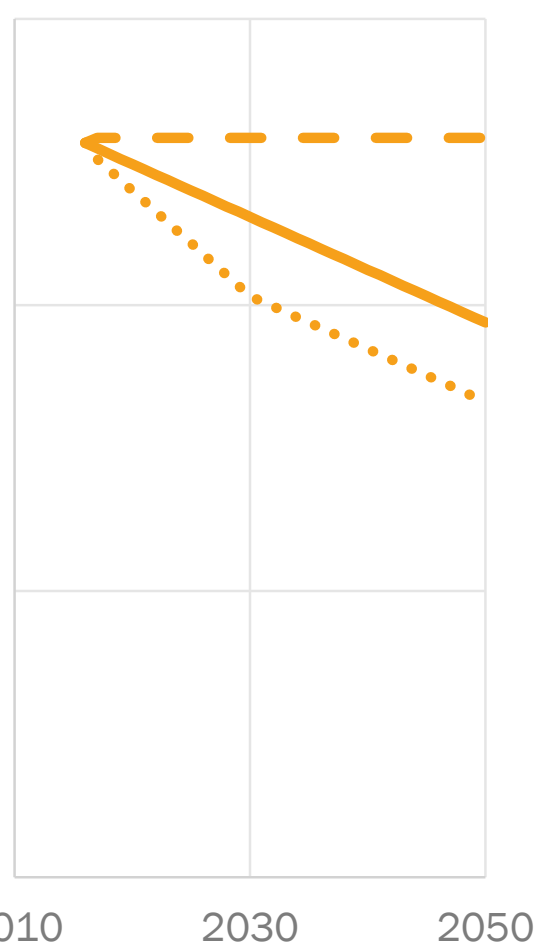

O\&M (\$/MWh)

For each TRG:

1. Report Base Year value for CAPEX, capacity factor, and O\&M, generally relying on market data

2. Develop future scenarios for CAPEX, capacity factor, and O\&M, generally relying on existing EERE/NREL work. 


\section{Example of Multiple LCOE Technology Cost Scenarios and Financial}

\section{Assumptions Cases: Land-Based Wind TRG4}

\section{LCOE $(\$ / M W h)$}

R\&D Only

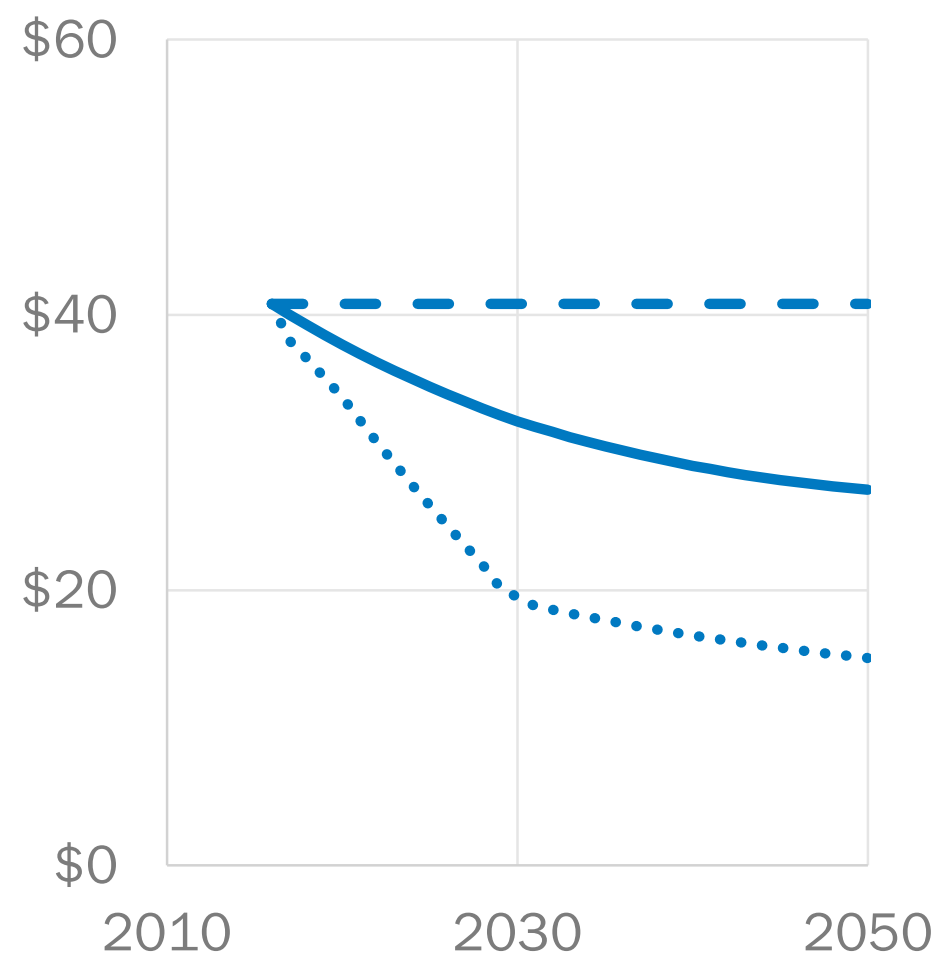

R\&D + Market Factors

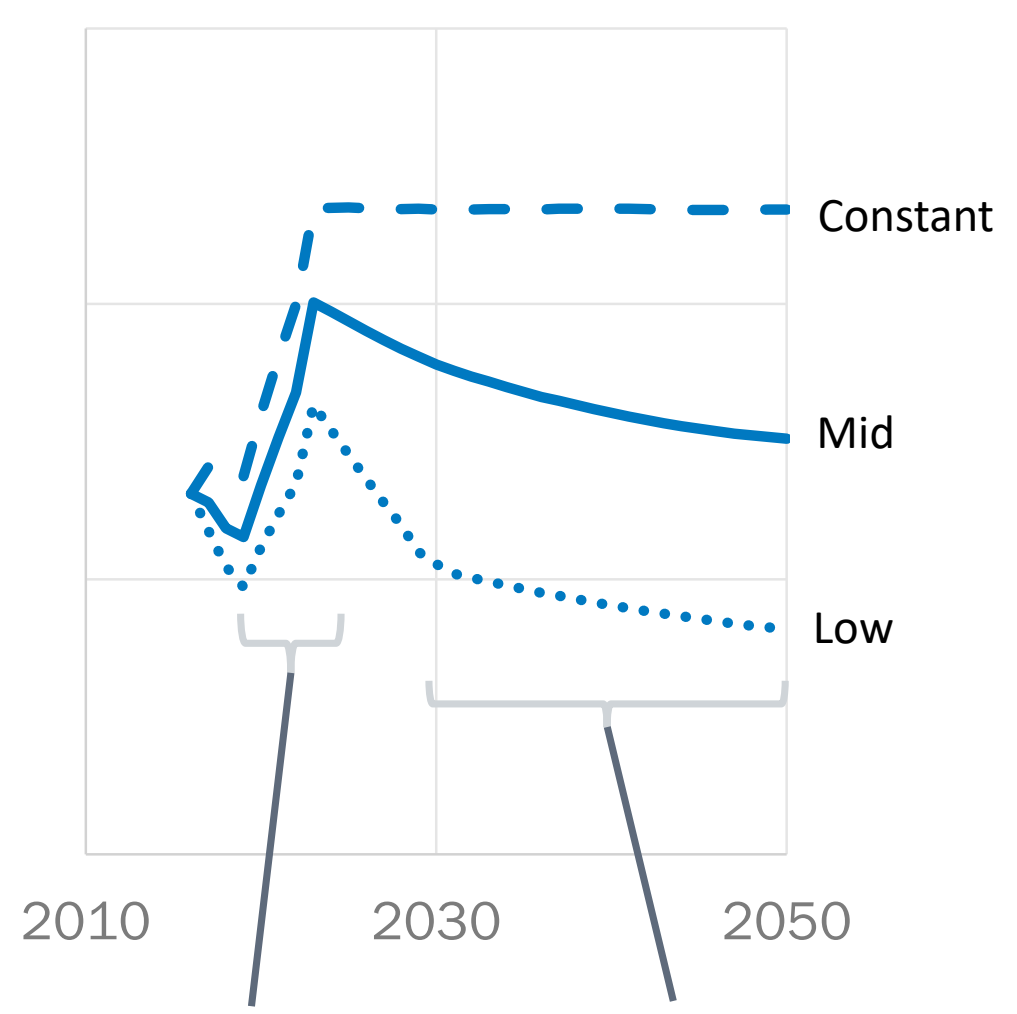

Rising interest rates, phase-out of production tax credit (PTC) 


\section{Projections Placed in Context of Past Trends ...}

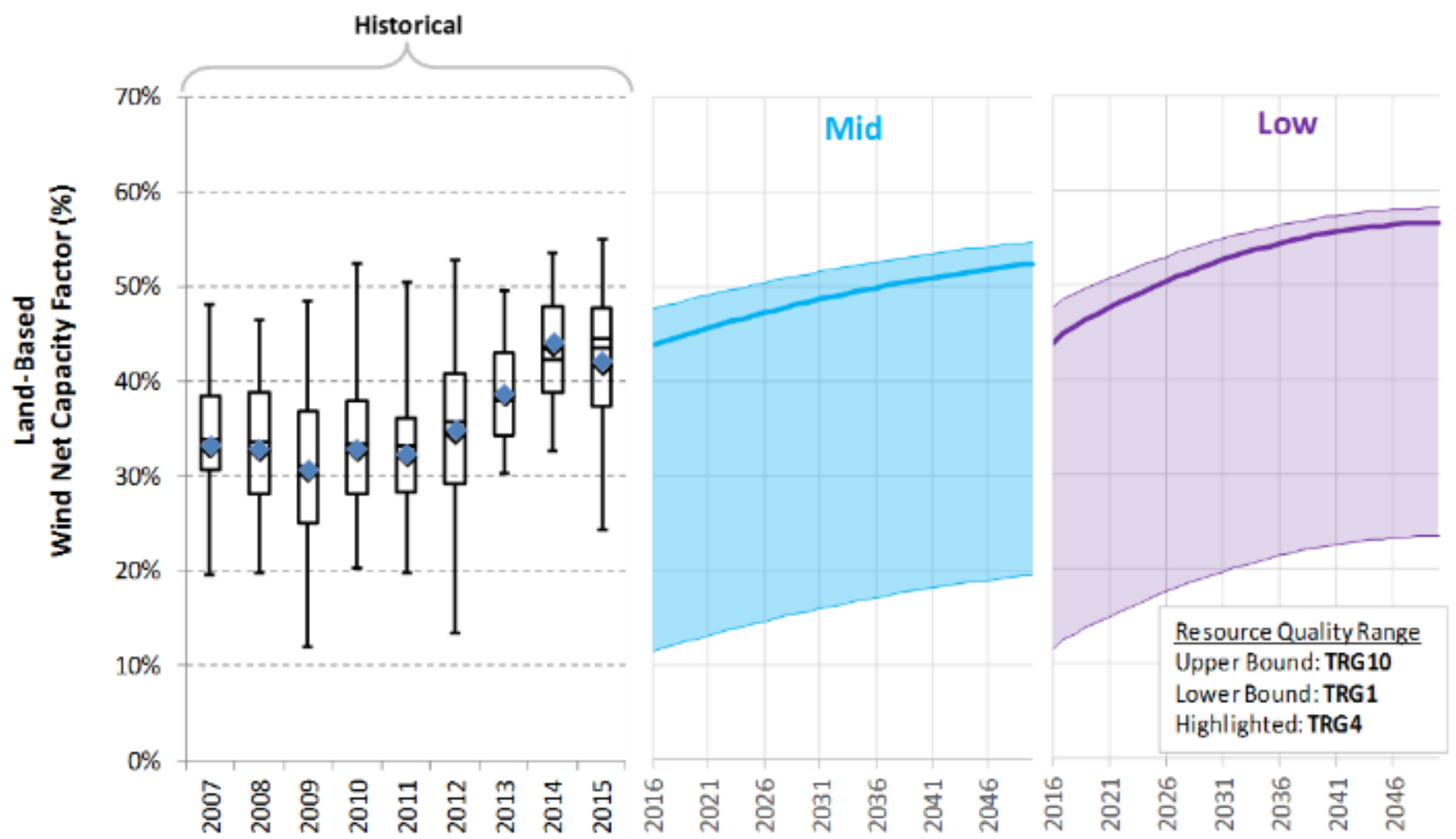

○ generation-weighted average, not in dex weighted

- generation-weighted average, wind index weighted

Source: National Renewable Energy Laboratory Annual Technology Baseline (2018), http://atb.nrel.gov 


\section{... and Projections from Other Sources}

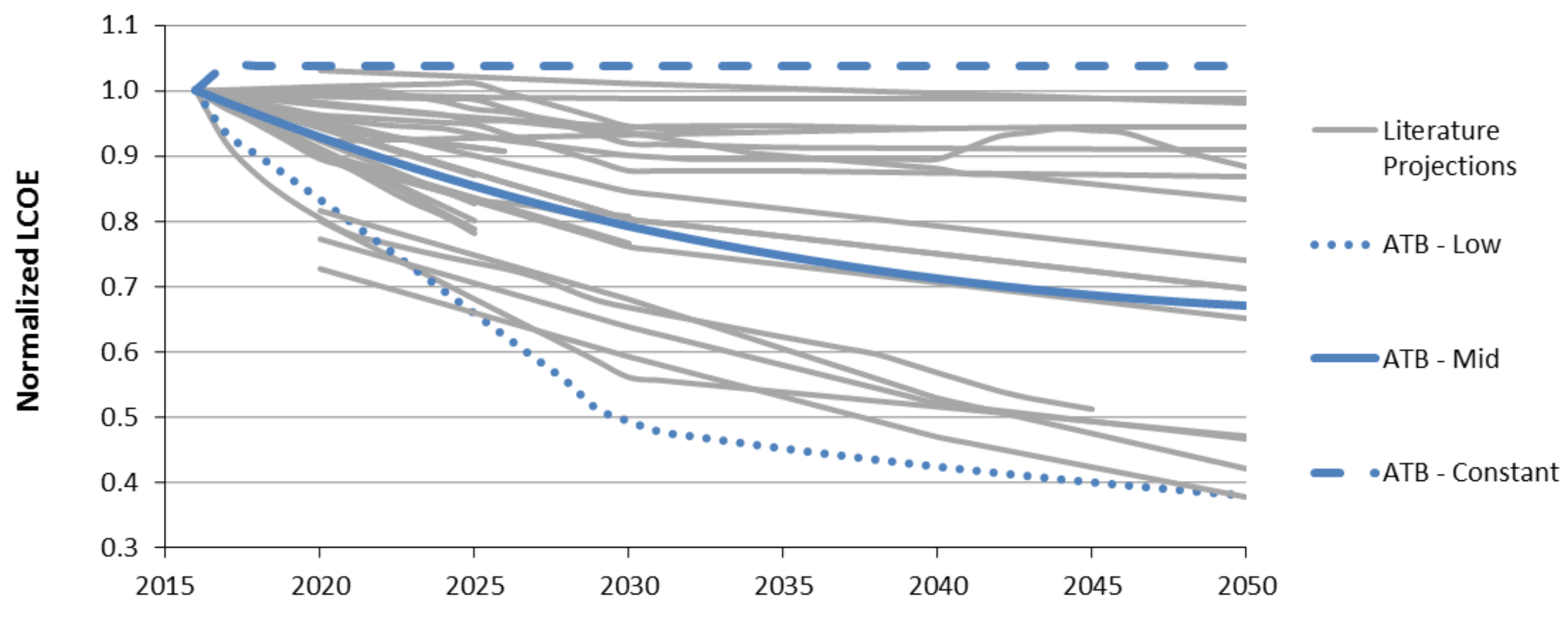

Land-based wind ATB cost projections compared with published literature

Source: National Renewable Energy Laboratory Annual Technology Baseline (2018), http://atb.nrel.gov 


\section{The 2018 ATB updates financial and technology assumptions.}

LCOE

Financial

Assumptions
Added technology-specific financing assumptions

Separated market effects on financing with an additional scenario

Extended default capital recovery period to 30 years

Technology- Wind: low case uses new SMART Wind report Specific Updates

PV: More granularity in resource quality

Geothermal: Geothermal Vision (when published)

Storage: ReEDS 8-hr Li-ion battery costs added 
Cost and Performance Summary 


\section{CAPEX Comparison, 2030}

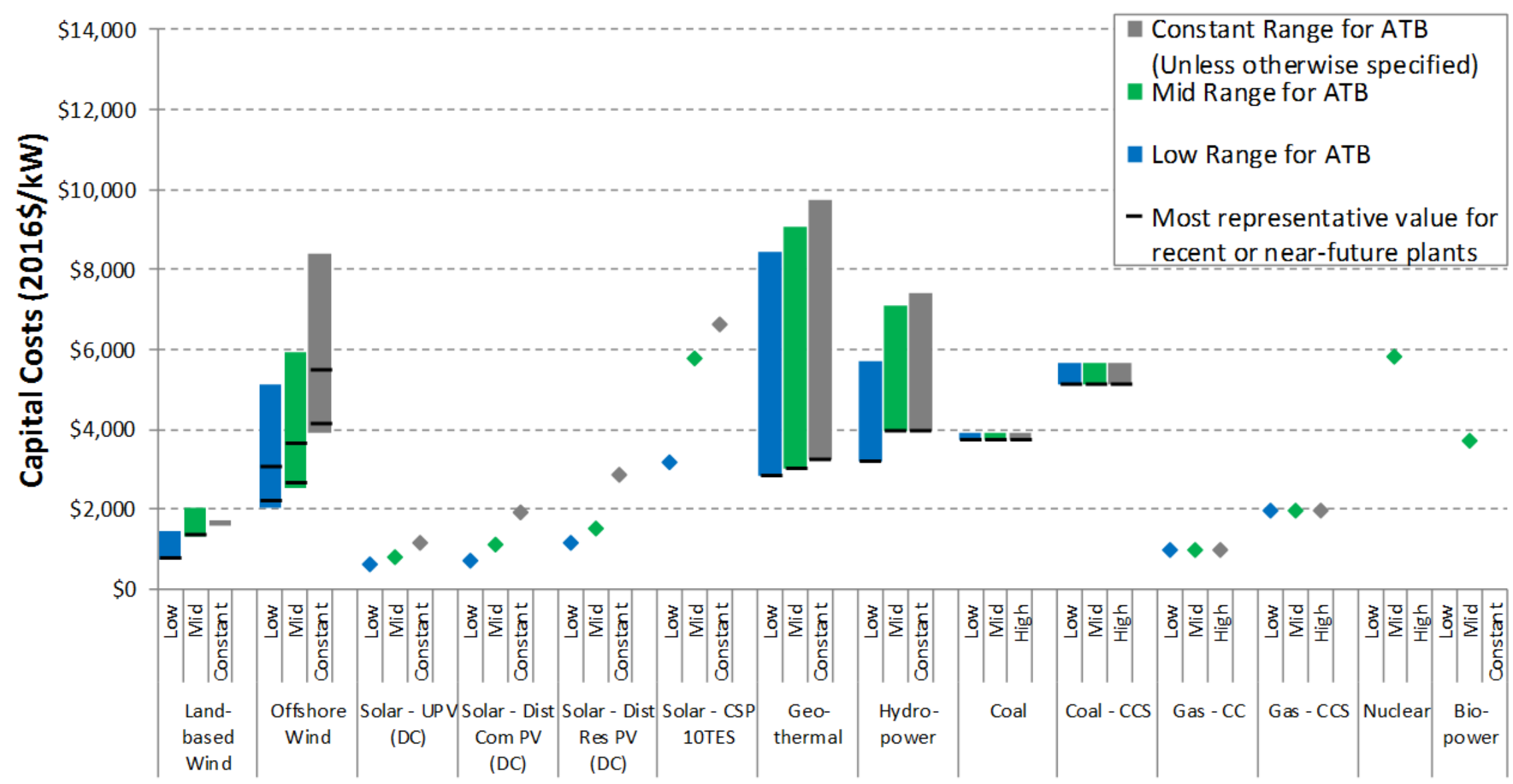

2018 ATB CAPEX range by technology for 2030

Source: National Renewable Energy Laboratory Annual Technology Baseline (2018), http://atb.nrel.gov 


\section{Capacity Factor Comparison, 2030}

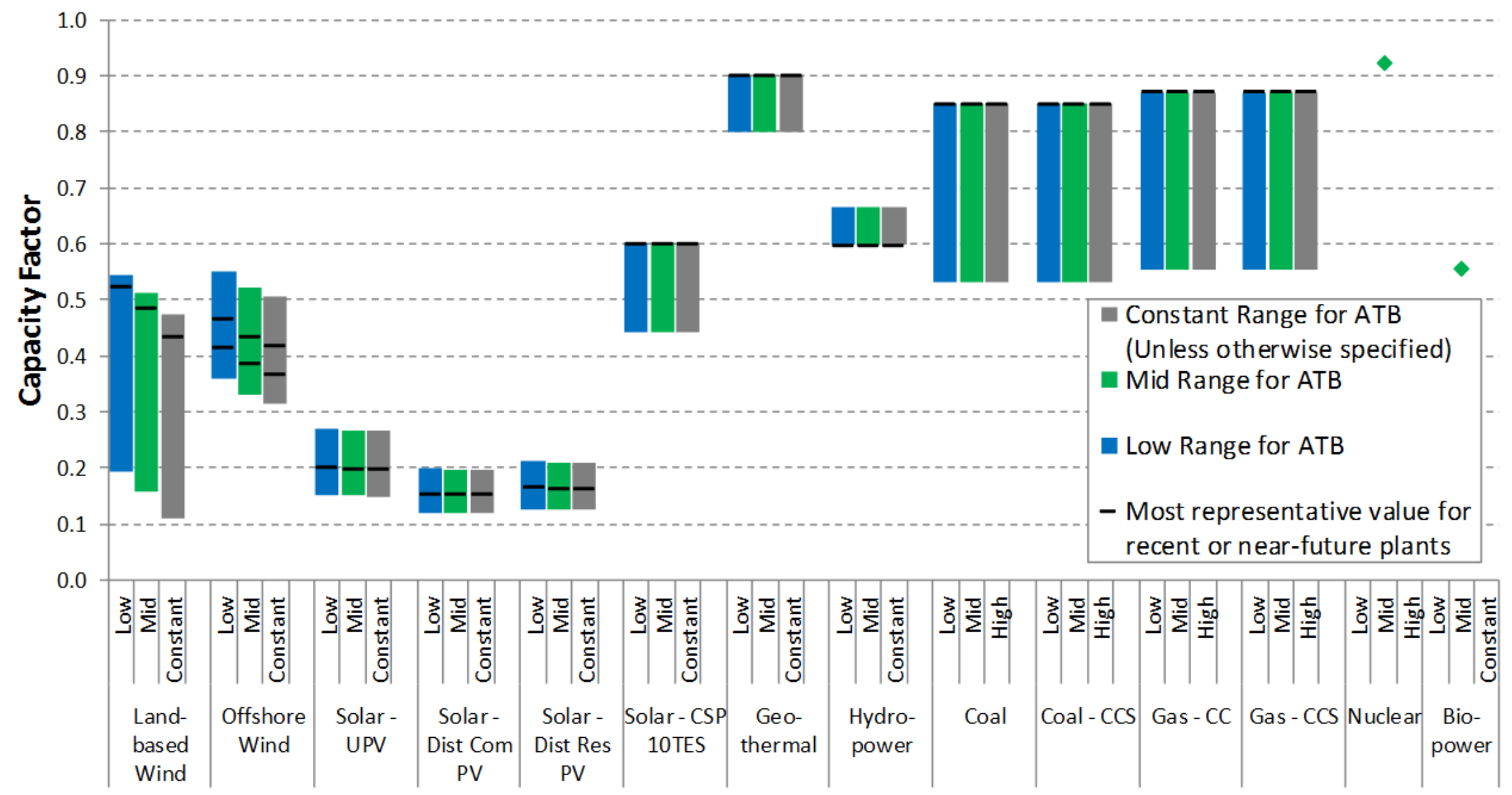

2018 ATB capacity factor range by technology for $\mathbf{2 0 3 0}$

Source: National Renewable Energy Laboratory Annual Technology Baseline (2018), http://atb.nrel.gov 


\section{LCOE, 2030}

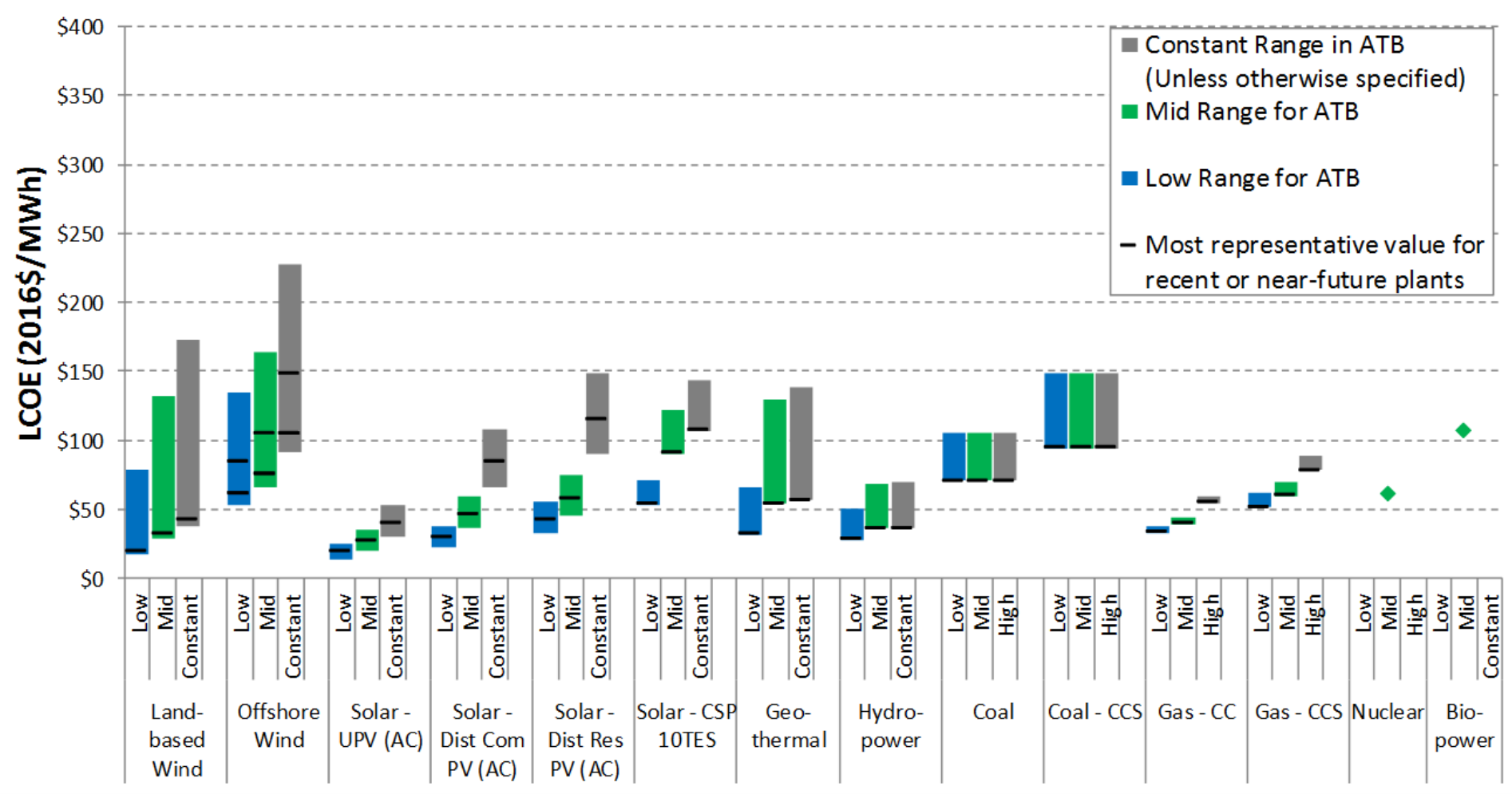

\section{ATB LCOE range by technology for $\mathbf{2 0 3 0}$ based on R\&D financial assumptions}

Source: National Renewable Energy Laboratory Annual Technology Baseline (2018), http://atb.nrel.gov

- Cost and performance improvements for wind, solar, geothermal, and hydropower technologies result in lower magnitude LCOE and tighter range across resource.

- The LCOE calculation includes dynamic effects of R\&D on technology cost, technology performance, and financial performance; with R\&D financial assumptions, the calculation excludes economic dynamics such as background changes to inflation, interest, and return on equity and also excludes policies such as tax credits and tariffs 


\section{LCOE Sensitivity to Cost Recovery Period}

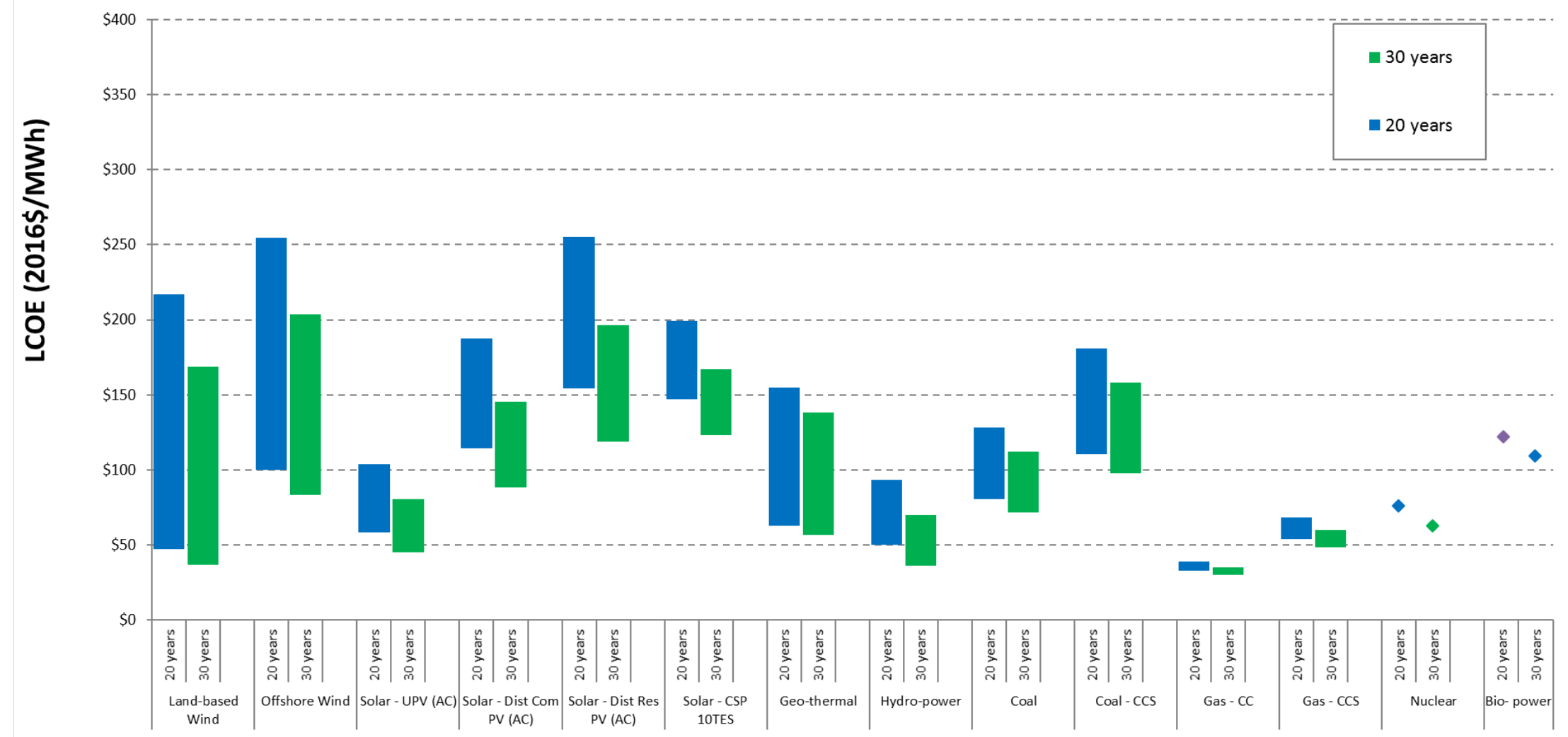

2018 ATB Base Year LCOE Sensitivity to Cost Recovery Period of Plant

Source: National Renewable Energy Laboratory Annual Technology Baseline (2018), http://atb.nrel.gov

- Cost recovery period is 30 years by default for all technologies.

- Cost recovery period of 20 years is shown for comparison.

- Spreadsheet users can input any cost recovery period. 


\section{LCOE Sensitivity to Financial Assumptions Case}

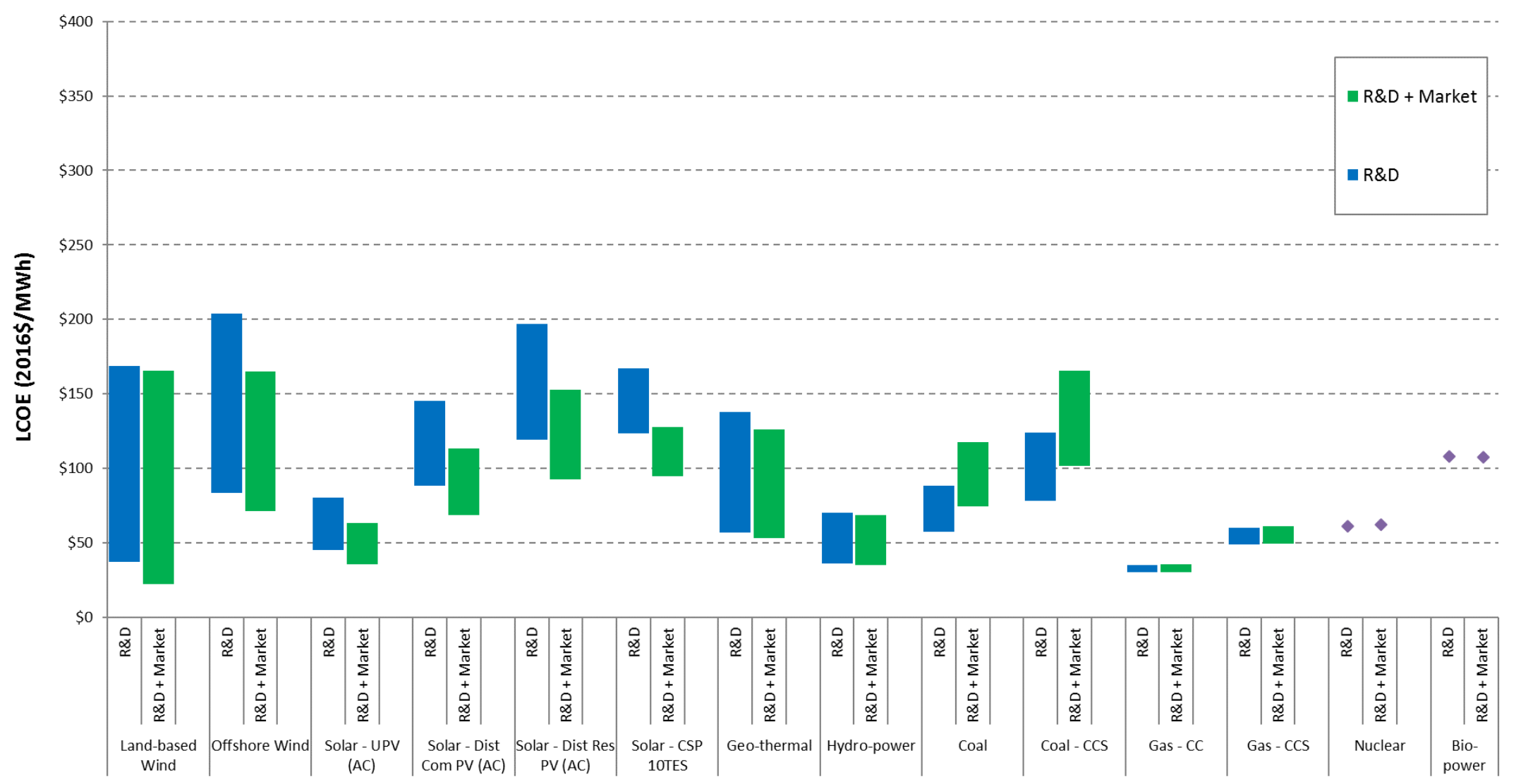

Sensitivity of 2016 Base Year LCOE to project finance parameters

Source: National Renewable Energy Laboratory Annual Technology Baseline (2018), http://atb.nrel.gov

- $R \& D=R \& D$ Only Financial Assumptions (constant background rates, no tax or tariff changes)

- $R \& D+$ Market $=$ R\&D Only + Market Financial Assumptions (dynamic background rates, taxes, and tariffs)

- ReEDS = ReEDS Financial Assumptions 


\section{Standard Scenarios Preview}




\section{Standard Scenarios}

- Covers more than 25 scenarios of the electricity sector

- Low/high fuel prices, demand, retirements, technology costs

- Various other futures such as low carbon scenarios, nuclear technology breakthrough, reduced transmission, and vehicle electrification

- Explores four areas of change in the electricity sector

- Evolving system operations with increasing penetration of renewable energy

- The potential for non-wind, non-PV renewable energy

- The impact of increasing natural gas and renewable energy deployment on energy prices

- What happens after the tax credits expire 


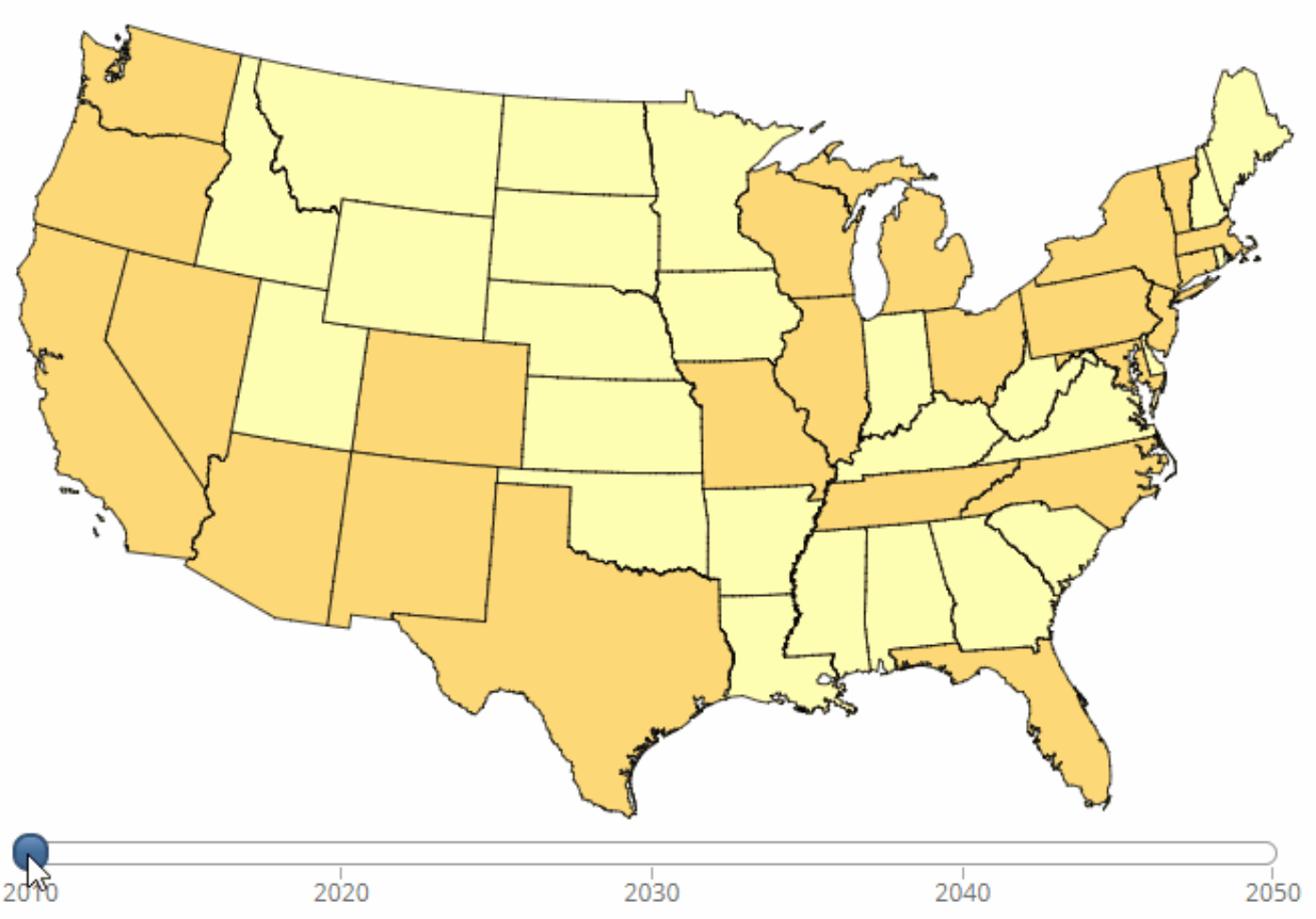

Publication Year

2017 -

Scenario 1:

Mid-Case Scenario -

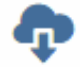

Scenario 2:

None -

Capacity (2010):

Utility PV (GW)

Capacity

Utility PV -

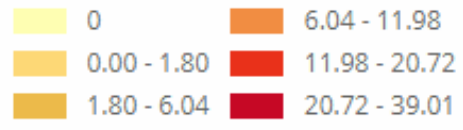

Compare Technologies

System Metrics

View and compare the contributions of each technology category to the total estimated generation or capacity.

\begin{tabular}{|c|c|}
\hline Select All & \\
\hline Biopower & CSP \\
\hline Coal & Geothermal \\
\hline Hydro & Land-based Wind \\
\hline NG-CC & NG-CT \\
\hline Nuclear & Offshore Wind \\
\hline Oil-Gas-Steam & Rooftop PV \\
\hline Storage & Utility PV \\
\hline
\end{tabular}

https://openei.org/apps/reeds/

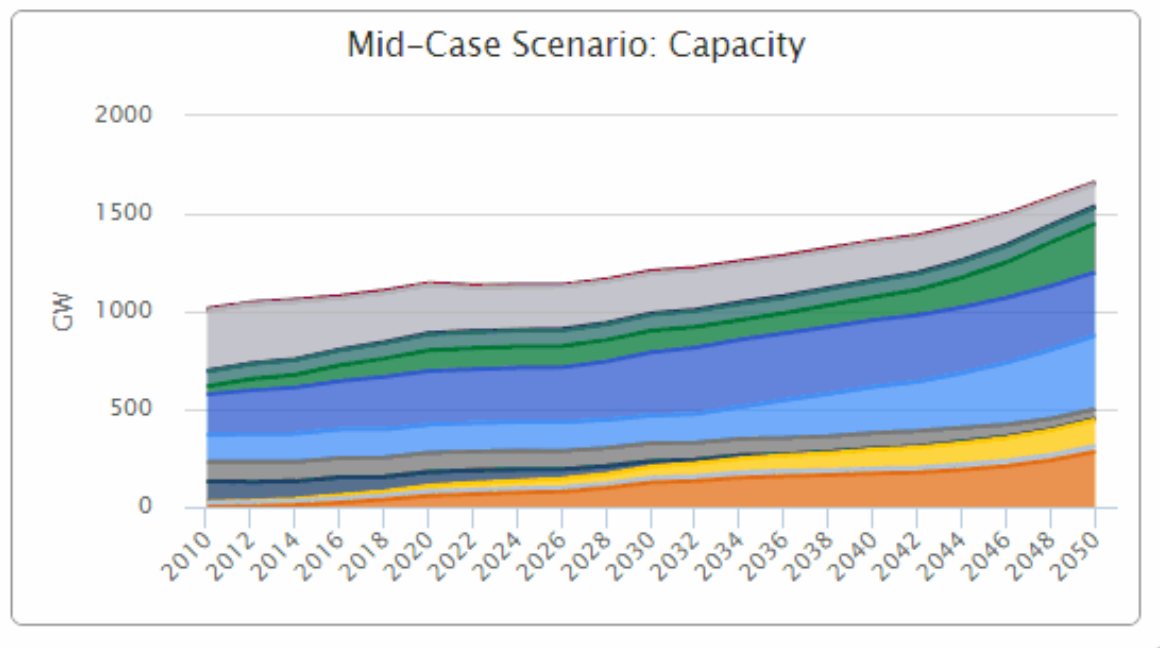




\section{Thank you!}

\section{The 2018 Annual Technology Baseline is available at atb.nrel.gov.}

For all references, see https://atb.nrel.gov/electricity/2018/references.html.

\section{www.nrel.gov}

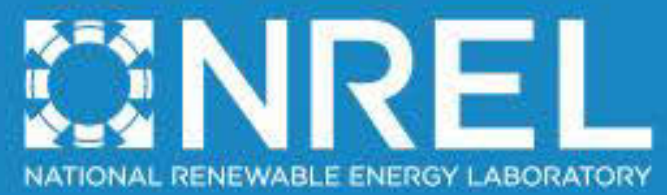

